\title{
Beneficial Effects of Mild Stress (Hormetic Effects): Dietary Restriction and Health
}

\author{
Katsuyasu Kouda and Masayuki Iki \\ Department of Public Health, Kinki University School of Medicine
}

\begin{abstract}
Hormesis is defined as a dose-response phenomenon characterized by low-dose stimulation and highdose inhibition, and has been recognized as representing an overcompensation for mild environmental stress. The beneficial effects of mild stress on aging and longevity have been studied for many years. In experimental animals, mild dietary stress (dietary restriction, DR) without malnutrition delays most age-related physiological changes, and extends maximum and average lifespan. Animal studies have also demonstrated that DR can prevent or lessen the severity of cancer, stroke, coronary heart disease, autoimmune disease, allergy, Parkinson's disease and Alzheimer's disease. The effects of DR are considered to result from hormetic mechanisms. These effects were reported by means of various DR regimens, such as caloric restriction, total-nutrient restriction, alternate-day fasting, and short-term fasting. Mild dietary stress, including restriction of amount or frequency of intake, is the essence of DR. For more than $99 \%$ of their history, humans lived as hunter-gatherers and adapted to restrictions in their food supply. On the other hand, an oversufficiency of food for many today has resulted in the current global epidemic of obesity and obesity-related diseases. DR may be used, therefore, as a novel approach for therapeutic intervention in several diseases, when detailed information about effects of mild dietary stress on human health is obtained from clinical trials. J Physiol Anthropol 29(4): 127-132, 2010 http://www.jstage.jst.go.jp/browse/jpa2
\end{abstract} [DOI: 10.2114/jpa2.29.127]

Keywords: diet, feeding behavior, physiological stress, prevention and control

\section{Dietary Restriction (DR) and Hormesis}

The hormetic dose-response model is the most common and fundamental in the biological and biomedical sciences (Calabrese, 2008b). Hormesis is defined as a dose-response phenomenon characterized by low-dose stimulation and highdose inhibition. This dose-response curve typically appears as an inverted U-shape or J-shape (Calabrese, 2008ab). Hormesis represents an overcompensation for mild environmental stress (Calabrese, 2001) and is the mechanism for adaptive responses to low doses of harmful environmental stimuli (Calabrese, 2008a). These harmful conditions include not only toxic substances, but also any environmental stimulus with potentially deleterious consequences for the organism, such as an increase or decrease in temperature. A stimulus that induces a beneficial hormetic response is called a mild stress (Le Bourg, 2009). Mild stress appears to slightly increase lifespan and to increase resistance to some stresses (Le Bourg, 2009).

Mild dietary stress (dietary restriction, DR) without malnutrition delays most age-related physiological changes and extends maximum and average lifespan in experimental animals (Weindruch and Sohal, 1997; Frame et al., 1998). The first evidence in rodents was reported by McCay et al. in 1935 (McCay et al., 1935). Since then, similar observations have been made in various species, including fish (Comfort, 1963), flies (Partridge et al., 1987), worms (Klass, 1977), and yeast (Lin et al., 2000). More recently, DR was reported to extend lifespan and increase disease resistance in primates (Colman et al., 2009). Lifespan extension by DR may occur in humans as well. In addition to lifespan extension, animal studies have demonstrated numerous beneficial effects of long-term DR. Long-term DR can prevent or lessen the severity of spontaneously occurring (Chen et al., 1990), chemicallyinduced (Birt et al., 1999), and radiation-induced neoplasia (Yoshida et al., 1997) in experimental animals. Chronic DR also reduces ischemic brain damage (Yu and Mattson, 1999) and protects the heart from ischemic injury (Ahmet et al., 2005). Furthermore, DR inhibits the development of autoimmune disease in several strains of mice (Kubo et al., 1992), and delays the onset and progression of spontaneous (Fan et al., 2001) and chemically-induced (Nakamura et al., 2004) allergic dermatitis. DR also increases resistance to neurotoxins in experimental models relevant to Parkinson's disease and Alzheimer's disease (Mattson et al., 2003). The DR-related increase in lifespan and protection against various diseases is likely mediated, in part, by hormetic mechanisms (Mattson, 2008). 


\section{Dietary Restriction (DR): Size or Frequency?}

These beneficial effects of DR were reported using various regimens in experimental animals. One DR regimen, chronic energy intake restriction, is performed by restricting daily total calorie intake using defined diets (Johnson et al., 1986; Chen et al., 1990) and is also called calorie restriction. Long-term total-nutrient restriction is a method that restricts total daily nutrient intake (Lueker et al., 1956). In total-nutrient restriction, the amount of food provided is adjusted daily to represent $60-80 \%$ of the food consumption of paired animals fed ad libitum (AL) (Fan et al., 2001). In general experimental studies, food is provided once daily. When DR animals are provided with food, they eat all of it within approximately 1 hour. After that, animals have no access to food and are under fasting conditions for the next 23 hours (Kouda et al., 2009).

Another DR regimen is alternate-day fasting (also called "intermittent fasting" or "every-other-day fasting"), in which animals alternate between days where they are fed AL and days of fasting (Goodrick et al., 1990). In this regimen, mice subjected to alternate-day fasting consume essentially the same amount of food in a 48-h period as those fed AL and eat roughly twice as much as AL-fed mice on days they can access food (Anson et al., 2003). There is no difference in body weight between alternate-day fasting mice and AL-fed mice (Anson et al., 2003). Thus, alternate-day fasting is a restriction in the frequency of food consumption, but not the amount of food consumption. Shorter periods of DR are also effective in protecting against environmental stress. For example, two days of water-only fasting induces differential stress resistance against oxidative stress in mice (Raffaghello et al., 2008) and suppresses chemically induced allergy in mice (Nakamura et al., 2001).

\section{Hormetic Mechanisms of Dietary Restriction (DR)}

In mild dietary stress, both the amount and frequency increase lifespan and protect against various diseases, in part, by hormetic mechanisms that increase cellular stress resistance (Mattson, 2008). One of the hormetic mechanisms contributing to the beneficial effects of DR is an increase in SIRT1 mRNA expression (Heilbronn et al., 2005a). SIRT1 is a key regulator of many cellular defenses that allow survival in response to stress (Motta et al., 2004). The increased longevity induced by DR in yeast requires the activation of $\operatorname{Sir} 2 p$, the homolog of mammalian SIRT1 (Lin et al., 2000). DR promotes mammalian cell survival by inducing SIRT1 (Cohen et al., 2004). It has been reported that three weeks of alternate-day fasting significantly increases expression of SIRTI in nonobese humans (Heilbronn et al., 2005a).

Increased levels of heat shock proteins (HSPs) by DR are considered another hormetic mechanism (Mattson, 2008). HSPs are stress proteins present in cells of all organisms, where they function as chaperones and play a crucial role in protecting cells from stress. HSPs are classified based on their molecular weight (e.g., hsp10, hsp40, hsp60, hsp70, hsp90) (Li and Srivastava, 2004). Caloric restriction has been reported to reverse the age-related decline in the induction of hsp70 transcription in rat hepatocytes (Heydari et al., 1993), and alternate-day fasting increases levels of Hsp70 protein in rat cortical synaptosomes (Guo et al., 2000).

It has been suggested that persistent glycolysis is deleterious due to the generation of methylglyoxal (Hipkiss, 2006). Methylglyoxal is formed predominantly from glycolytic intermediates, and rapidly glycates proteins and damages mitochondria. In a general DR regimen, food is provided once daily. When DR animals are provided with food, they eat all of it within approximately 1 hour. After that, animals are under fasting conditions for the next 23 hours (Kouda et al., 2009). Daily restricted animals are glycolytic for the first 12 hours after feeding and then obtain energy from fat metabolism during the subsequent 12 hours (Kouda et al., 2009), and glycolysis is suppressed (McCarter and Palmer, 1992). Consequently, it can be argued that the beneficial effects of DR are derived partly from the suppression of glycolysis (Hipkiss, 2006).

\section{Humans and Obesity}

Today, there are two serious problems concerning diet and health. The first is malnutrition (marasmus) due to serious food shortage. The second is obesity from overeating. The human lineage diverged from that of chimpanzees about 6 to 7 million years ago (Brunet et al., 2002). For more than $99 \%$ of its history, most humans lived as hunter-gatherers. They adapted to restrictions in their food supply (Zimmet and Thomas, 2003). In contrast, many people living in today's modern technological society can obtain more than enough food. The adoption of a regular intake of high-calorie foods has resulted in the current global epidemic of obesity (Zimmet and Thomas, 2003). Dietary patterns shift rapidly, particularly in the developing world, resulting in major shifts in obesity globally (Popkin and Gordon-Larsen, 2004).

\section{Feeding Frequency and Obesity}

Our ancestors could not eat three meals every day. They consumed meals much less frequently, and often consumed one large meal per day or went for several days without food. Thus, they were adapted to intermittent fasting and intermittent AL feeding (Mattson, 2005).

Despite the lack of strong scientific evidence, health care professionals believe that consuming smaller meals more frequently is healthier than consuming larger meals less frequently (Mattson, 2005). Indeed, several epidemiological studies have reported an inverse relationship between high meal frequency and obesity. However, a recent review of epidemiological studies concluded that the evidence is at best very weak, and almost certainly represents an artifact (Bellisle et al., 1997). Consistent with this, one randomized controlled 
trial reported that meal frequency and a period of fasting have no major impact on energy intake in obese patients (Taylor and Garrow, 2001). Several important errors in the epidemiological studies have also been reported. The most important issue is dietary under-reporting in overweight people. Discrepancies between self-reported and actual caloric intake in overweight people can lead to artifacts in the results (Livingstone et al., 1990; Lichtman et al., 1992). The validity of meal frequency estimates in epidemiological studies is also very weak at best (Mattson, 2005).

Many observational studies report that breakfast frequency is inversely associated with obesity and chronic disease. Breakfast is considered the most important meal of the day. Most health care professionals believe, therefore, that skipping breakfast is a risk factor for obesity. However, this conclusion has important limitations. It has been reported that skipping breakfast demonstrates no substantial or significant association with mortality after multivariate adjustment (Wingard et al., 1982), and that the average total energy intake is significantly lower in children who skipped breakfast than children who consumed breakfast (Nicklas et al., 1993). Thus, not all studies associate skipping breakfast with obesity. Recently, one systematic review concluded that many observation studies have important limitations, that there are only four relatively small and short-term randomized trials, and that these studies concluded mixed results (Timlin and Pereira, 2007). Thus, the relationship between breakfast consumption and body weight is not well established (Rampersaud et al., 2005). To conclude an association between breakfast frequency and health, more well-designed work, such as randomized controlled studies or cross-over studies, is required in the future.

\section{Intermittent Fasting in Humans}

Fasting is obligatory for all healthy adult Muslims during the month of Ramadan. Ramadan fasting is intermittent, because food and water intake is permissible from sunset to dawn (Al Suwaidi et al., 2004). Body weight decreases slightly during this month. Ramadan fasting has been shown to reduce lowdensity lipoprotein (LDL) levels and increase high-density lipoprotein (HDL) levels (Lamri-Senhadji et al., 2009). The increase of HDL and apoprotein A1, and the decrease in LDL that occur with fasting can be beneficial for the cardiovascular system (Adlouni et al., 1997; Roky et al., 2004). The effects of alternate-day fasting in humans have also been reported: nonobese participants fasted from midnight to the subsequent midnight on alternating days for 22 days and lost $2.5 \%$ of their initial body weight and $4.1 \%$ of their initial fat mass (Heilbronn et al., 2005b).

\section{Dietary Restriction (DR) for Future Clinical Use}

Animal studies have shown that DR can prevent or lessen the severity of cancer (Chen et al., 1990), stroke (Yu and Mattson, 1999), coronary heart disease (Ahmet et al., 2005), autoimmune disease (Kubo et al., 1992), allergy (Nakamura et al., 2004), and Parkinson's disease and Alzheimer's disease (Mattson et al., 2003). Thus, evidence is now strong for the association between DR and disease protection in experimental animals. However, there is a substantial shortage of information concerning the usefulness of DR as clinical therapy and disease prevention in humans. It is known that obesity in humans is related to diseases such as coronary heart disease, cancer, atherosclerosis, hypertension, and diabetes mellitus. DR is considered essential in clinical therapy for the prevention of obesity. On the other hand, evidence of the beneficial effects on human health is weak, except for obesityrelated diseases. Recent epidemiological studies indicate that individuals with a low daily caloric intake have a reduced risk for Parkinson's disease (Logroscino et al., 1996) and Alzheimer's disease (Luchsinger et al., 1999). These epidemiological studies are consistent with the results of animal studies. Concerning inflammatory disease, a relationship between asthma and obesity has been suggested in several epidemiological studies (Story, 2007). In a clinical study, a low-energy diet reduced inflammatory symptoms and oxidative damage in patients with atopic dermatitis (Kouda et al., 2000). A case of a patient with atopic dermatitis and repeated one day fasting has also been reported (Nakamura et al., 2003). Furthermore, rapid and sustained beneficial effects of alternate-day calorie restriction in overweight adults with asthma have been recently reported (Johnson et al., 2007). These beneficial effects on allergic disease are consistent with the results of an animal study (Fan et al., 2001). Fasting (Kjeldsen-Kragh et al., 1991) and a low-energy diet (Iwashige et al., 2004) have been reported to be effective treatments for patients with rheumatoid arthritis. The effect of fasting was assessed in a randomized, single-blind controlled trial (Kjeldsen-Kragh et al., 1991). This beneficial effect on autoimmune disease is also consistent with the results of an animal study (Kubo et al., 1992). However, to demonstrate an evidence of clinical use, there are still few data about the DR and human inflammatory disease. Numerous well-designed clinical studies, such as randomized controlled studies or cross-over studies, are needed to obtain detailed information about the effects of mild dietary stress and human health.

\section{Conclusions}

In experimental animals, the beneficial effects of DR without malnutrition on disease prevention and lifespan extension have been studied for many years. Mild dietary stress, including restriction of amount or frequency of intake, is the essence of DR (hormetic effects). Lifespan extension by DR may occur in humans as well. DR may be used, therefore, as a novel approach for therapeutic intervention in several diseases, when detailed information about the effects of mild dietary stress on human health is obtained from clinical trials.

Acknowledgements There is no conflict of interest that 
might bias our paper. The authors would like to thank Prof. Hiroichi Takeuchi, Prof. Rikio Tokunaga, and Prof. Harunobu Nakamura for their support. The paper is dedicated to Dr. Mitsuo Kouda (1924-2008).

\section{References}

Adlouni A, Ghalim N, Benslimane A, Lecerf JM, Saile R (1997) Fasting during Ramadan induces a marked increase in high-density lipoprotein cholesterol and decrease in lowdensity lipoprotein cholesterol. Ann Nutr Metab 41: 242-249

Ahmet I, Wan R, Mattson MP, Lakatta EG, Talan M (2005) Cardioprotection by intermittent fasting in rats. Circulation 112: 3115-3121

Al Suwaidi J, Bener A, Suliman A, Hajar R, Salam AM, Numan MT, Al Binali HA (2004) A population based study of Ramadan fasting and acute coronary syndromes. Heart 90: 695-696

Anson RM, Guo Z, de Cabo R, Iyun T, Rios M, Hagepanos A, Ingram DK, Lane MA, Mattson MP (2003) Intermittent fasting dissociates beneficial effects of dietary restriction on glucose metabolism and neuronal resistance to injury from calorie intake. Proc Natl Acad Sci USA 100: 6216-6220

Bellisle F, McDevitt R, Prentice AM (1997) Meal frequency and energy balance. Br J Nutr 77 Suppl 1: S57-70

Birt DF, Yaktine A, Duysen E (1999). Glucocorticoid mediation of dietary energy restriction inhibition of mouse skin carcinogenesis. J Nutr 129: 571S-574S

Brunet M, Guy F, Pilbeam D, Mackaye HT, Likius A, Ahounta D, Beauvilain A, Blondel C, Bocherens H, Boisserie JR, De Bonis L, Coppens Y, Dejax J, Denys C, Duringer P, Eisenmann V, Fanone G, Fronty P, Geraads D, Lehmann T, Lihoreau F, Louchart A, Mahamat A, Merceron G, Mouchelin G, Otero O, Pelaez Campomanes P, Ponce De Leon M, Rage JC, Sapanet M, Schuster M, Sudre J, Tassy P, Valentin X, Vignaud P, Viriot L, Zazzo A, Zollikofer C (2002) A new hominid from the Upper Miocene of Chad, Central Africa. Nature 418: 145-151

Calabrese EJ (2001) Overcompensation stimulation: a mechanism for hormetic effects. Crit Rev Toxicol 31: 425-470

Calabrese EJ (2008a) Converging concepts: adaptive response, preconditioning, and the Yerkes-Dodson Law are manifestations of hormesis. Ageing Res Rev 7: 8-20

Calabrese EJ (2008b) Hormesis and medicine. Br J Clin Pharmacol. 66: 594-617

Chen RF, Good RA, Engelman RW, Hamada N, Tanaka A, Nonoyama M, Day NK (1990) Suppression of mouse mammary tumor proviral DNA and protooncogene expression: association with nutritional regulation of mammary tumor development. Proc Natl Acad Sci USA 87: 2385-2389

Cohen HY, Miller C, Bitterman KJ, Wall NR, Hekking B, Kessler B, Howitz KT, Gorospe M, de Cabo R, Sinclair DA
(2004) Calorie restriction promotes mammalian cell survival by inducing the SIRT1 deacetylase. Science 305: 390-392

Colman RJ, Anderson RM, Johnson SC, Kastman EK, Kosmatka KJ, Beasley TM, Allison DB, Cruzen C, Simmons HA, Kemnitz JW, Weindruch R (2009) Caloric restriction delays disease onset and mortality in rhesus monkeys. Science 325: 201-204

Comfort A (1963) Effect of delayed and resumed growth on the longevity of a fish (Lebistes Reticulatus, Peters) in captivity. Gerontologia 49: 150-155

Fan W, Kouda K, Nakamura H, Takeuchi H (2001) Effects of dietary restriction on spontaneous dermatitis in $\mathrm{NC} / \mathrm{Nga}$ mice. Exp Biol Med (Maywood) 226: 1045-1050

Frame LT, Hart RW, Leakey JE (1998) Caloric restriction as a mechanism mediating resistance to environmental disease. Environ Health Perspect 106 Suppl 1: 313-324

Goodrick CL, Ingram DK, Reynolds MA, Freeman JR, Cider N (1990) Effects of intermittent feeding upon body weight and lifespan in inbred mice: interaction of genotype and age. Mech Ageing Dev 55: 69-87

Guo Z, Ersoz A, Butterfield DA, Mattson MP (2000) Beneficial effects of dietary restriction on cerebral cortical synaptic terminals: preservation of glucose and glutamate transport and mitochondrial function after exposure to amyloid beta-peptide, iron, and 3-nitropropionic acid. J Neurochem 75: 314-320

Heilbronn LK, Civitarese AE, Bogacka I, Smith SR, Hulver M, Ravussin E (2005a) Glucose tolerance and skeletal muscle gene expression in response to alternate day fasting. Obes Res 13: 574-581

Heilbronn LK, Smith SR, Martin CK, Anton SD, Ravussin E (2005b) Alternate-day fasting in nonobese subjects: effects on body weight, body composition, and energy metabolism. Am J Clin Nutr 81: 69-73

Heydari AR, Wu B, Takahashi R, Strong R, Richardson A (1993) Expression of heat shock protein 70 is altered by age and diet at the level of transcription. Mol Cell Biol 13: 2909-2918

Hipkiss AR (2006) On the mechanisms of ageing suppression by dietary restriction-is persistent glycolysis the problem? Mech Ageing Dev 127: 8-15

Iwashige K, Kouda K, Kouda M, Horiuchi K, Takahashi M, Nagano A, Tanaka T, Takeuchi H (2004) Calorie restricted diet and urinary pentosidine in patients with rheumatoid arthritis. J Physiol Anthropol Appl Human Sci 23: 19-24

Johnson BC, Gajjar A, Kubo C, Good RA (1986) Calories versus protein in onset of renal disease in NZB $x$ NZW mice. Proc Natl Acad Sci USA 83: 5659-5662

Johnson JB, Summer W, Cutler RG, Martin B, Hyun DH, Dixit VD, Pearson M, Nassar M, Telljohann R, Maudsley S, Carlson O, John S, Laub DR, Mattson MP (2007) Alternate day calorie restriction improves clinical findings and reduces markers of oxidative stress and inflammation in overweight adults with moderate asthma. Free Radic Biol Med 42: $665-674$ 
Kjeldsen-Kragh J, Haugen M, Borchgrevink CF, Laerum E, Eek M, Mowinkel P, Hovi K, Forre O (1991) Controlled trial of fasting and one-year vegetarian diet in rheumatoid arthritis. Lancet 338: 899-902

Klass MR (1977) Aging in the nematode Caenorhabditis elegans: major biological and environmental factors influencing life span. Mech Ageing Dev 6: 413-429

Kouda K, Kohno H, Nakamura H, Ha-Kawa SK, Sonoda Y, Iki M (2009) Technetium-99m-GSA clearance in mice under long-term dietary restriction. Ann Nucl Med 23: 123-129

Kouda K, Tanaka T, Kouda M, Takeuchi H, Takeuchi A, Nakamura H, Takigawa M (2000) Low-energy diet in atopic dermatitis patients: clinical findings and DNA damage. J Physiol Anthropol Appl Human Sci 19: 225-228

Kubo C, Gajjar A, Johnson BC, Good RA (1992) The effects of dietary restriction on immune function and development of autoimmune disease in BXSB mice. Proc Natl Acad Sci USA 89: 3145-3149

Lamri-Senhadji MY, El Kebir B, Belleville J, Bouchenak M (2009) Assessment of dietary consumption and time-course of changes in serum lipids and lipoproteins before, during and after Ramadan in young Algerian adults. Singapore Med J 50: 288-294

Le Bourg E (2009) Hormesis, aging and longevity. Biochim Biophys Acta 1790: 1030-1039

Li Z, Srivastava P (2004) Heat-shock proteins. Curr Protoc Immunol Appendix 1, Appendix 1T

Lichtman SW, Pisarska K, Berman ER, Pestone M, Dowling H, Offenbacher E, Weisel H, Heshka S, Matthews DE, Heymsfield SB (1992) Discrepancy between self-reported and actual caloric intake and exercise in obese subjects. N Engl J Med 327: 1893-1898

Lin SJ, Defossez PA, Guarente L (2000) Requirement of NAD and SIR2 for life-span extension by calorie restriction in Saccharomyces cerevisiae. Science 289: 2126-2128

Livingstone MB, Prentice AM, Strain JJ, Coward WA, Black AE, Barker ME, McKenna PG, Whitehead RG (1990) Accuracy of weighed dietary records in studies of diet and health. BMJ 300: 708-712

Logroscino G, Marder K, Cote L, Tang MX, Shea S, Mayeux R (1996). Dietary lipids and antioxidants in Parkinson's disease: a population-based, case-control study. Ann Neurol 39: 89-94

Luchsinger JA, Tang MX, Shea S, Mayeux R (2002). Caloric intake and the risk of Alzheimer disease. Arch Neurol 59: 1258-1263

Lueker CE, Meyer JH, Smith JD (1956) Influence of food and energy restriction and subsequent recovery on body composition and food utilization of rats. J Nutr 60: 121-128

Mattson MP (2005) The need for controlled studies of the effects of meal frequency on health. Lancet 365: 1978-1980

Mattson MP (2008) Dietary factors, hormesis and health. Ageing Res Rev 7: 43-48

Mattson MP, Duan W, Guo Z (2003) Meal size and frequency affect neuronal plasticity and vulnerability to disease: cellular and molecular mechanisms. J Neurochem 84: 417-431

McCarter RJ, Palmer J (1992) Energy metabolism and aging: a lifelong study of Fischer 344 rats. Am J Physiol 263: E448-452

McCay CM, Crowel MF, Maynard LA (1935) The effect of retarded growth upon the length of life span and upon the ultimate body size. J Nutr 10: 63-79

Motta MC, Divecha N, Lemieux M, Kamel C, Chen D, Gu W, Bultsma Y, McBurney M, Guarente L (2004) Mammalian SIRT1 represses forkhead transcription factors. Cell 116: 551-563

Nakamura H, Kouda K, Fan W, Watanabe T, Takeuchi H (2001) Suppressive effects on allergic contact dermatitis by short-term fasting. Toxicol Pathol 29: 200-207

Nakamura H, Kouda K, Tokunaga R, Takeuchi H (2004) Suppressive effects on delayed type hypersensitivity by fasting and dietary restriction in ICR mice. Toxicol Lett 146: 259-267

Nakamura H, Shimoji K, Kouda K, Tokunaga R, Takeuchi H (2003) An adult with atopic dermatitis and repeated shortterm fasting. J Physiol Anthropol Appl Human Sci 22: 237-240

Nicklas TA, Bao W, Webber LS, Berenson GS (1993) Breakfast consumption affects adequacy of total daily intake in children. J Am Diet Assoc 93: 886-891

Partridge L, Green A, Fowler K (1987) Effects of eggproduction and of exposure to males on female survival in Dorsophila melanogaster. J Insect physiol 33: 745-749

Popkin BM, Gordon-Larsen P (2004) The nutrition transition: worldwide obesity dynamics and their determinants. Int $\mathrm{J}$ Obes Relat Metab Disord 28 (Suppl 3): S2-9

Raffaghello L, Lee C, Safdie FM, Wei M, Madia F, Bianchi G, Longo VD (2008) Starvation-dependent differential stress resistance protects normal but not cancer cells against highdose chemotherapy. Proc Natl Acad Sci USA 105: 82158220

Rampersaud GC, Pereira MA, Girard BL, Adams J, Metzl JD (2005) Breakfast habits, nutritional status, body weight, and academic performance in children and adolescents. J Am Diet Assoc 105: 743-760, 761-742

Roky R, Houti I, Moussamih S, Qotbi S, Aadil N (2004) Physiological and chronobiological changes during Ramadan intermittent fasting. Ann Nutr Metab 48: 296-303

Story RE (2007) Asthma and obesity in children. Curr Opin Pediatr 19: 680-684

Taylor MA, Garrow JS (2001) Compared with nibbling, neither gorging nor a morning fast affect short-term energy balance in obese patients in a chamber calorimeter. Int $\mathrm{J}$ Obes Relat Metab Disord 25: 519-528

Timlin MT, Pereira MA (2007) Breakfast frequency and quality in the etiology of adult obesity and chronic diseases. Nutr Rev 65: 268-281

Weindruch R, Sohal RS (1997) Seminars in medicine of the Beth Israel Deaconess Medical Center. Caloric intake and 
aging. N Engl J Med 337: 986-994

Wingard DL, Berkman LF, Brand RJ (1982) A multivariate analysis of health-related practices: a nine-year mortality follow-up of the Alameda County Study. Am J Epidemiol 116: 765-775

Yoshida K, Inoue T, Nojima K, Hirabayashi Y, Sado T (1997) Calorie restriction reduces the incidence of myeloid leukemia induced by a single whole-body radiation in C3H/He mice. Proc Natl Acad Sci USA 94: 2615-2619

Yu ZF, Mattson MP (1999) Dietary restriction and 2deoxyglucose administration reduce focal ischemic brain damage and improve behavioral outcome: evidence for a preconditioning mechanism. J Neurosci Res 57: 830-839
Zimmet P, Thomas CR (2003) Genotype, obesity and cardiovascular disease--has technical and social advancement outstripped evolution? J Intern Med 254: $114-125$

Received: March 31, 2010

Accepted: June 3, 2010

Correspondence to: Katsuyasu Kouda, Department of Public Health, Kinki University School of Medicine, 377-2 OonoHigashi, Osaka-Sayama, Osaka 589-8511, Japan

Phone: +81-72-366-0221

Fax: +81-72-367-8262

e-mail:kouda@med.kindai.ac.jp 